\title{
AS CONTRIBUIÇÕES DO PSICOPEDAGOGO NO ÂMBITO ESCOLAR
}

\author{
Gerson de Sousa Batista ${ }^{1}$ \\ Eliane Carvalho Vidal Dias ${ }^{2}$ \\ Aretuza Silva de Figueiredo ${ }^{3}$ \\ Raquel dos Santos de Sousa ${ }^{4}$ \\ Jeane Karine Silva Moura ${ }^{5}$ \\ Grasielle Verônica Rosa ${ }^{6}$
}

RESUMO: O cenário educacional vigente nota-se a ocorrência de vários estudos significativos voltado para as áreas da educação que são fundamentais para o avanço $e$ definição de novos conceitos relacionados a processo de ensino-aprendizagem, sendo que diante dessas inovações emergentes no contexto da sociedade contemporânea a psicopedagogia passou a ser considerada como algo relevante as instituições de ensino. Tendo como objetivo geral: Apontar a importância do trabalho do psicopedagogo nas instituições de ensino. A abordagem desse estudo tem como procedimento técnico o estudo bibliográfico, sendo a pesquisa de cunho qualitativo. Com base nas fundamentações teóricas utilizadas na pesquisa percebe-se que o papel do psicopedagogo nas instituições de ensino é algo relevante na contemporaneidade, porque a escola recebe influência do meio, sendo isso um determinante do perfil e das relações sociais dos sujeitos na sociedade, meio a esses aspectos a atuação do psicopedagogo precisa ser compreendido como algo favorável a qualidade do ensino.

PALAVRAS-CHAVES: Psicopedagogo. Espaço escolar. Processo formativo.

\section{INTRODUÇÃO}

Observando o panorama educacional vigente percebe-se que há inúmeros estudos significativos voltado para as áreas da educação que são essenciais para o avanço e definição de novos conceitos relacionados a processo de ensino-aprendizagem, partindo dessas inovações no contexto da sociedade contemporânea a Psicopedagogia tem ganhado destaque nas instituições de ensino.

\footnotetext{
I Formado em Direito pela Universidade Estadual do Piauí e em Letras Português pela Universidade Federal do Piauí. E-mail: Adv.gerson38@gmail.com

2 Formação em Licenciatura Plena em Pedagogia pela Universidade Federal do Pará. E-mail: Eliane.dias@ifpa.edu.br

3 Formação em Enfermagem pela Universidade Federal de Alfenas - Minas Gerais. E-mail: aretuzasilvadefigueiredo@gmail.com

${ }^{4}$ Formação em Pedagogia pela Faculdade Visconde de Cairu.E-mail: Raquelsousazi@yahoo.com.br

${ }^{5}$ Com formação em Letras Português e Pedagogia pela Universidade Federal do Piauí. E-mail: jeanekarinephb@hotmail.com

${ }^{6}$ Formação em Licenciatura Plena em Educação Física pela Universidade Estadual de Goiás. Unidade Quirinópolis. E-mail: 6r45II@gmail.com
} 
Desse modo a Psicopedagogia tem como ápice de estudo a aprendizagem, sendo que esse foco surgiu da necessidade de compreender o processo de aprendizagem dos sujeitos, considerando as suas limitações e dificuldades que interferem o processo de consolidação do conhecimento.

É perceptível que estamos inseridos no contexto da contemporaneidade, com isso torna-se fundamental compreender e reconhecer, que esse cenário de transformações resulta em mudanças perceptíveis nas mais variadas fases do desenvolvimento da criança, partindo desse princípio surge a necessidade de considerar as contribuições da diversidade de profissionais que são relevantes a educação no espaço educativo, a exemplo tem-se o psicopedagogo, fonoaudiólogo, etc. As contribuições de outros profissionais no âmbito escolar nos direcionam a uma reflexão com relação a qualidade do processo ensino-aprendizagem no campo minada das dificuldades de aprendizagem. Para Almeida:

\begin{abstract}
Atualmente, com o aumento significativo do fracasso escolar por diversos motivos, como sócio-cultural, conflitos familiares, sistemas pedagógicos, deficiência intelectual e inibição intelectual, as escolas e as famílias têm buscado na Psicopedagogia a resolução para problemas de alunos com dificuldade de aprendizagem nas diferentes áreas do desenvolvimento. (2010, p. o9).
\end{abstract}

Diante dos inúmeros empecilhos emergentes no contexto escolar nota-se que a atuação de profissionais que irão auxiliar o trabalho dos professores meio as dificuldades é algo significativo, com isso o trabalho da Psicopedagogia é indispensável no panorama educacional vigente, pois este profissional evita e reduz possíveis dificuldades de aprendizagem, além de ser favorável nas relações existentes no espaço educativo.

\footnotetext{
Cabe ao psicopedagogo perceber eventuais perturbações no processo aprendizagem, participar da dinâmica da comunidade educativa, favorecendo a integração, promovendo orientações metodológicas de acordo com as características e particularidades dos indivíduos do grupo, realizando processos de orientação. Já que no caráter assistencial, o psicopedagogo participa de equipes responsáveis pela elaboração de planos e projetos no contexto teórico/prático das políticas educacionais, fazendo com que os professores, diretores e coordenadores possam repensar o papel da escola frente a sua docência $e$ às necessidades individuais de aprendizagem da criança ou, da própria ensinagem. (BOSSA, 1994, p. 23).
}

Considerando relevância do trabalho do psicopedagogia no âmbito educacional e suas incumbências só pode atuar como psicopedagogo os profissionais habilitados em 
cursos de extensão Latu sensu em psicopedagogia com o devido registro conforme a Resolução I2/83, de 06/10/83.

\begin{abstract}
A primeira universidade a oferecer o curso de graduação em Psicopedagogia foi a Pontifícia Universidade Católica do Rio Grande do Sul (PUC/RS), no ano de 2005, e o primeiro Mestrado acadêmico, com área de atuação em Psicopedagogia, foi em 2006, pelo CAPES, que é o Centro de Atenção Psicossocial. A regulamentação brasileira teve avanço a partir do Projeto de Lei no $128 / 2000$ e da Lei no 10.891 . Entretanto, a regulamentação de qualquer nova profissão, a exemplo da psicanálise, tem encontrado uma forte barreira constitucional, pois o Art. $5^{\mathrm{o}}$ da Constituição Brasileira prevê o "livre exercício profissional", o que deixa claro que o profissional de Psicopedagogia pode exercer sua profissão quando necessário e solicitado pela comunidade.
\end{abstract}

A regulamentação nos cursos de pós-graduação em Psicopedagogia, coordenada pelo MEC, dá a este profissional competência para exercer suas atividades em empresas, clínicas, hospitais e escolas. A lei vigente que dá a formação do psicopedagogo é a Resolução ${ }_{12} / 83$, de o6/10/83 - que forma os especialistas, no caso, os então chamados "especialistas em psicopedagogia" ou psicopedagogos. A instituição que oferece o curso tem que estar de acordo com as normas educacionais para emitir certificados de pós-graduação. (MOTA, R. V. e. S; FREIRE FA, L. G; POLETTO, L, 2016, p. 7I-72).

Considerando o exposto anteriormente com a intenção de refletir sobre as contribuições da Psicopedagogia com relação ao desenvolvimento humano no espaço educativo, o presente estudo apresenta como objetivo geral: Apontar a importância do trabalho do psicopedagogo nas instituições de ensino e objetivos específicos: Compreender a função do psicopedagogo no panorama educacional vigente; Identificar a relevância da atuação desse profissional nas escolas; Elencar as atribuições do psicopedagogo.

O panorama educacional atual está permeada inúmeros problemas que prejudicam o processo de ensino-aprendizagem, como também a consolidação de habilidades imprescindíveis ao desenvolvimento integral dos sujeitos, por conta disso torna-se fundamental apresentar estudos que destacam a relevância do psicopedagogo na formação holística dos alunos, pois a Psicopedagogia precisa ser compreendida como uma ferramenta favorável ao processo formativo. Conforme a Lei de Diretrizes e Bases da Educação Nacional/96 (LDB) no Art. 29. “A educação infantil, primeira etapa da educação básica, tem como finalidade o desenvolvimento integral da criança de até 5 (cinco) anos, em seus aspectos físico, psicológico, intelectual e social, complementando a ação da família e da comunidade.” (Brasil, 1996, p. 13).

Gaddotti apresenta a seguinte formulação sobre educação integral: 
Experiências e análises sobre o tema estão ocorrendo em diferentes partes do Brasil. Mas, o tema não é novo; é tema recorrente, desde a antiguidade. Aristóteles já falava em educação integral. Marx preferia chamá-la de educação "omnilateral”. A educação integral, para Aristóteles, era a educação que desabrochava todas as potencialidades humanas. (2009, p. 21).

O estudo apropriou-se de uma pesquisa de cunho qualitativo de caráter bibliográfico, sendo que esse procedimento pode ser caracterizado como um mecanismo que utiliza como ponto central das reflexões a diversidade de produções escritas que norteiam o estudo, ou seja, essa variedade escrita serve como fundamentação para as reflexões no decorrer das discussões considerando a problemática em estudo.

[...] Bibliografia é o conjunto dos livros escritos sobre determinado assunto, por autores conhecidos e identificados ou anônimos, pertencentes a correntes de pensamento diversas entre si, ao longo da evolução da humanidade. E a pesquisa bibliográfica consiste no exame desse manancial, para levantamento e análise do que já se produziu sobre determinado assunto que assumimos como tema de pesquisa cientifica. (RUIZ, 2002, p.58).

Embasaram as reflexões ao longo do trabalho os seguintes autores: ALMEIDA (2004), BOSSA (1994), BRUM, F. T; PAVÃO, S. M (2014), GADOTTI (2009), MENDES (2016), entre outros. Desse modo é importante destacar que as bases teóricas são fundamentais, pois demarcam as bases necessárias para uma reflexão crítica com relação a problemática em discussão, objetivando o alcance de resultados significativos na pesquisa.

\section{O PANORAMA HISTÓRICO DA PSICOPEDAGOGIA NO CONTEXTO ESCOLAR}

No cenário educacional pode-se perceber existe inúmeros fatores no âmbito escolar que afetam diretamente a aprendizagem, como resultante desse contexto árduo surge a aproximadamente na década de quarenta a Psicopedagogia objetivando compreender e intervir no processo de complexidade da aprendizagem, conforme Almeida (2004, p. II).

Desse modo compreende-se a relevância do psicopedagogo no espaço educativo, mas cabe destacar, que a Psicopedagogia não se limita apenas fornecer suporte para os sujeitos com dificuldades de aprendizagem, pois seu campo de estudo é a aprendizagem de maneira ampla, partindo desse princípio percebe-se que a mesma é indispensável 
para os sujeitos independente de particularidades, pelo fato de ser um suporte eficaz e eficiente para uma aprendizagem de qualidade.

A Psicopedagogia apresenta como bases a literatura francesa em meados do século XXI, pois esse período pode ser considerado como marco do surgimento de pesquisas inovadoras relacionadas aos problemas de aprendizagem, passou a ser observado a interferência do meio no processo de aprendizagem dos sujeitos.

As preocupações com os problemas de aprendizagem se originaram na Europa, no século XIX, época em que se consolidava o capitalismo industrial. As dificuldades de aprendizagem despertaram interesse em alguns estudiosos e assim passaram a ser foco de atenção. A medicina começou um profundo estudo e investigações das causas dos problemas e suas possíveis correções, a área Oftalmológica, a Neurológica e a Psiquiatria entre outros profissionais da saúde fizeram parte desses estudos, pois através deles era dado um diagnóstico final. No final do século XIX, Educadores, Psiquiatras e Neuropsiquiatras começaram a se preocupar com os aspectos que interferiam na aprendizagem e organizavam métodos para a educação infantil. (MOTA, R. V. e. S; FREIRE FA, L. G; POLETTO, L, 2or6, p. 69).

No território brasileiro a Psicopedagogia surgiu no período de 1950 tendo como marco o surgimento de estudos voltados a mesma.

O professor e médico argentino Júlio Bernaldo de Quiros, que participava dos grupos que atuavam com a problemática de aprendizado no sentido de organizar os núcleos, dedicou-se a pesquisas de leitura-escrita durante muito tempo e o resultado dessa experiência foi sua publicação nas décadas de 1950 e I960, o qual ele destaca suas experiências. Seus trabalhos foram muitos, tanto na Argentina como também no Brasil.

Conta-se também com profissionais de Porto Alegre, que inaugurou Centro de Estudos destinados à Formação em Psicopedagogia. O professor Nilo Fichtner fundou o Centro de Estudos Médicos e Psicopedagógicos, no Rio Grande do Sul. A essa formação dá-se um quadro de referências baseado em um modelo médico de atuação. (MOTA, R. V. e. S; FREIRE FA, L. G; POLETTO, L, 2016, p. 72).

Considerando o exposto anteriormente percebe-se que o Brasil foi fortemente influenciado pelos movimentos americanas e europeus, com isso emerge desse contexto a necessidade de profissionais capacitados em Psicopedagogia, sendo que no decorrer do trajeto histórico os psicopedagogos defrontaram-se com inúmeros desafios, a exemplo pode-se apontar a consolidação do aparato legal quanto a atuação desse profissional no país, a Lei no $3124 / 97$.

Em 1997, foi encaminhado à Câmara dos Deputados o Projeto de Lei no 3.124 que tratava da regulamentação da Profissão do Psicopedagogo, que em síntese diz que: o Psicopedagogo é o profissional que auxilia na identificação e resolução dos problemas no processo de aprender. O Psicopedagogo está 
capacitado a lidar com as dificuldades de aprendizagem, um dos fatores que leva à multirrepetência e à evasão escolar, conduzindo à marginalização social. (SILVA, 2007, p. 20).

A Leia apontada acima regulamenta a atuação do psicopedagogo no território brasileiro, pois a mesma fornece subsídios necessários ao desempenho desse profissional, considerando a relevância e eficácia do mesmo com relação a compreensão do processo de aprendizagem permeado pelas particularidades de cada sujeito, colaborando com o rendimento escolar, sendo que a formalização da Lei n⿳o 3124/97 ocorreu em 1997, com o intuito de inserir esse profissional no âmbito escolar.

A Psicopedagogia no contexto brasileiro ganha destaque também a partir da aprovação do Projeto de Lei no 128 em São Paulo, o mesmo permite a implantação de assistência psicológica e psicopedagógica nas instituições públicas, com a finalidade de identificar de modo preventivo por meio de diagnósticos as dificuldades de aprendizagem. "A regulamentação brasileira teve avanço a partir do Projeto de Lei no ı28/2000 e da Lei no ıo.89ı”. (MOTA, R. V. e. S; FREIRE FA, L. G; POLETTO, L, 2016, p. 7I).

Considerando o aparato legal citado acima, cabe ressaltar que existem outros importantes ao processo de histórico de regulamentação da atuação do psicopedagogo como profissional fundamental para a qualidade do ensino frente as inúmeras dificuldades de aprendizagem presentes no cenário educacional.

\section{A SIGNIFICÂNCIA DO PSICOPEDAGOGO NO AMBIENTE ESCOLAR}

Os estabelecimentos de ensino são responsáveis pela formação dos sujeitos para atuar na sociedade, mas os docentes constantemente deparam-se com inúmeras situações, que dificultam o processo de ensino-aprendizagem que retrata um baixo rendimento no espaço escolar.

É fundamental identificar as diversas situações e problemas que dificultam o processo de ensino-aprendizagem, com isso é notório as contribuições e o papel da Psicopedagogia no âmbito escolar, pois o psicopedagogo analisa o processo de aprendizagem permeada pela complexidade das sala de aula, por conta disso o trabalho do psicopedagogo torna-se algo indispensável na redução de problemas relacionados a aprendizagem e fracasso escolar. 
Cabe ao profissional com formação psicopedagógica, nomeado de especialista em Psicopedagogia, o papel de entender a aprendizagem em seus limites ou dificuldades e em suas potencialidades, intervindo nos casos que se fizerem necessários. Essa ação vai além de um bom aporte teórico e prático, e pode remeter a uma atuação mais sensível às características do ser humano na sociedade. Decorre dessa compreensão a atuação do psicopedagogo nas formas preventiva e terapêutica, compreendendo os processos do desenvolvimento e das aprendizagens humanas. (BRUM, F. T; PAVÃO, S. M. de. O, 2014, p. IIo).

Frente ao explanado anteriormente percebe-se que o psicopedagogo apresenta incumbências imprescindíveis nas instituições de ensino, pois a ação desse profissional abrange estudantes, assim como toda comunidade que está relacionada com os espaços educativo. Dessa forma o psicopedagogo apresenta habilidades necessárias para identificar problemas de aprendizagem, apontando técnicas de intervenção para solucionar/reduzir as dificuldades de aprendizagem dos alunos.

Em consequência disso, o papel do psicopedagogo destaca-se por seu caráter interdisciplinar, pois sua intervenção no âmbito escolar alcança dimensões muito específicas do trabalho psicopedagógico, tendo ele que usar ferramentas para avaliar, diagnosticar e intervir, alcançando as dimensões da família (dinâmica, estrutura) e da escola (curriculares, metodológicos). (BRUM, F. T; PAVÃO, S. M. de. O, 2014, p. i17).

A atuação do psicopedagogo na escola não se limita apenas a aprendizagem, pois é indispensável também ao ensino considerando a ação docente, pelo fato de apontar possibilidades importantes a prática pedagógica com relação a obtenção de objetivos propostos ao processo de ensino-aprendizagem.

O psicopedagogo no âmbito educativo atual tem conquistado sua significância, porque sua ação está direcionada ao caráter preventivo das inúmeras dificuldades de aprendizagem presentes nas escolas, com isso a atuação desse profissional reflete significativamente na qualidade da educação, ou seja, a ação do psicopedagogo considera aspectos relevante ao processo formativo como por exemplo: planejamento, estratégias didáticas, metodológicas, etc.

Portanto, o psicopedagogo é um sujeito fundamental e crucial, pelo fato de auxiliar de maneira significativa o processo formativo dos sujeitos, ou seja, torna-se uma base expressiva para alunos, professores, família, etc. Dessa forma o aluno não pode ser responsabilizado pelo seu fracasso de maneira isolada, pois no cenário atual é emergencial identificar as causas das dificuldades de aprendizagem presentes nas instituições de ensino para que possa obter melhorias necessárias com relação ao alcance 
da tão almejada qualidade do ensino, para que isso aconteça torna-se indispensável a atuação do psicopedagogo e outros profissionais que precisam assessorar a educação, o professor sozinho não é capaz de fornecer um aparato que determinará a melhoria da educação.

\section{CONSIDERAÇÕES FINAIS}

Considerando a problemática desse estudo percebe-se a importância do psicopedagogo nas instituições de ensino, sendo que essa percepção é oriunda das bases teóricas fundamentais as análises e reflexões pertinentes a temática abordada, pois evidenciou que esse profissional é uma peça chave na identificação de problemas de aprendizagem.

A eficácia e eficiência na resolução de problemas de aprendizagem de maneira consistente precisa da parceira do psicopedagogo e todos os envolvidos no processo formativo do aluno, mas cabe destacar que apesar da relevância desse profissional nos estabelecimentos de ensino o mesmo defronta-se com um problema corriqueiro que é a ausência de regulamentação do seu trabalho de maneira efetiva nas escolas.

Desse modo, existem poucos estudos que abordam a importância do psicopedagogo na escola como um determinante da melhoria da aprendizagem nesse espaço, mas os referenciais teóricos encontrados foram significantes para a reflexão e consolidação de proposições relacionadas ao trabalho relevante desse profissional no âmbito escolar.

É perceptível a utilidade do psicopedagogo no combate do fracasso escolar, mas para que vias de fato isso ocorra torna-se necessário políticas públicas que reconheçam a importância desse profissional na escola e que promovam a regularização para que o mesmo exerça sua função.

O trabalho ativo do psicopedagogo em conformidade com outros apoios fundamentais na escola deve ser considerado um promotor de resultados significativos a educação, com relação a redução de problemas de aprendizagem que emanam no contexto escolar. Segundo Mendes “[...] considerando-se que o psicopedagogo conheça a realidade em que o professor atua, observe sua dinâmica pedagógica e reelabore junto 
com ele a conduta pedagógica mais adequada à realidade de sua sala de aula.” (2016, p. $70)$.

Portanto, considerando todas essas proposições verifica-se que o papel do psicopedagogo em instituições públicas ou privadas é algo considerável e pertinente no contexto social vigente, pois a escola é fortemente influenciada pelos fatores que delimitam o perfil e as relações sociais dos sujeitos na contemporaneidade, com isso a atuação desse profissional nas escolas pode ser compreendida como algo favorável a qualidade do ensino.

Espera-se que a pesquisa torne-se relevante para trabalhos posteriores, que possa contribuir com novos estudos direcionados a temática em questão, porque o mesmo apresenta reflexões críticas relacionadas a ação do psicopedagogo nas instituições de ensino.

\section{REFERÊNCIAS BIBLIOGRÁFICAS}

ALMEIDA, I.S. de. A importância de um psicopedagogo em uma instituição escolar. 2004 . Disponível em:

http://www.avm.edu.br/docpdf/monografias_publicadas/iror333.pdf. Acessado em 20 de outubro de 2018.

BOSSA, Nádia A. A Psicopedagogia no Brasil: contribuições a partir da prática. Porto Alegre: Artmed, 1994 .

BRASIL, Legislação. Lei de Diretrizes e Bases da Educação: Lei no 9.394, de 20 de dezembro de 1996. Disponível em: portal.mec.gov.br/componente/article?id=I2907: legislações. Acesso em 13 de abril de 2016.

BRUM, F. T; PAVÃO, S. M. de. O. Espaços psicopedagógicos na escola: legitimados ou urgentes? Rev. Psicopedagogia, v. 3I, n. 95, p. I09-II8, 2014. Disponível em: http://pepsic.bvsalud.org/pdf/psicoped/v3In95/o4.pdf. Acessado em is de outubro de 2018.

GADOTTI, M. Educação integral no Brasil: inovações em processo. São Paulo. Editora e livraria Instituto Paulo Freire, 2009.

MENDES, M. Portfólio: instrumento de metacognição para os Professores em seu processo reflexivo na atividade docente. Rev. Psicopedagogia, 2016. Disponível em: 
https://www.abpp.com.br/revistas/revista-psicopedagogia-ıoo.pdf. Acessado em 28 de outubro de 2018 .

MOTA, R. V. e. S; FREIRE FA, L. G; POLETTO, L. Psicopedagogia: a prática do psicopedagogo no ambiente escolar. UC - Unicamps Ciência. 20I6. Disponível em: http://www.unicampsciencia.com.br/pdf/579e8780749c6.pdf. Acessado em is de outubro de 2018.

RUIZ, João Álvaro. Metodologia Científica: guia para eficiência nos estudos. São Paulo: Atlas, 2002.

SILVA, C. P. Psicologia - Contribuições e desafios. Disponível em: https://www.avm.edu.br/docpdf/monografias_publicadas/posdistancia/28473.pdf.

Acessado em 20 de outubro de 2018. 